\title{
The production, morphology, karyotypes and transport of spermatozoa from tertiary trisomic mice and the consequences for egg fertilization
}

\author{
P. de Boer, F. A. van der Hoeven and J. A. P. Chardon \\ Department of Genetics, Agricultural University, Wageningen, The Netherlands*
}

\begin{abstract}
Summary. Tertiary trisomic males, carrying the small translocation chromosome from the $\mathrm{T}(1 ; 13) 7 \mathrm{OH}$ reciprocal mouse translocation as the extra chromosome, are oligospermic. Uterine and oviductal sperm counts were $\bumpeq 10 \%$ of normal. Of the uterine spermatozoa, $77 \cdot 2 \%$ were morphologically abnormal compared with $24.6 \%$ in the oviduct. Oligospermy in the tertiary trisomic males leads to delayed fertilization; $34.8 \%$ of the 109 eggs scored between $5 \cdot 5-9 \cdot 5 \mathrm{hr}$ after mating were fertilized compared with $52.1 \%(n=343)$ at Day 2 . Of the 179 morulae/blastocysts recovered at Day 4, $46.9 \%$ contained the small marker chromosome, which agrees with earlier cytological studies on secondary spermatocytes. These results indicate that euploid and aneuploid spermatozoa are formed in about equal numbers and there is no relationship between sperm morphology and karyotype.
\end{abstract}

\section{Introduction}

Reciprocal translocations can lead to numerical unequal segregation during anaphase of the first meiotic division. From all mouse reciprocal translocations known, this behaviour is evident in those having one very small translocation chromosome, often not bound by a chiasma to the other chromosomes of the translocation multivalent. When the small translocation chromosomesegregates with the two normal chromosomes involved in the translocation, a tertiary trisomic zygote is produced which can prove to be viable at birth.

Male tertiary trisomics recovered up to now in the mouse have been sterile, but when the extra chromosome constitutes the small translocation chromosome of the $\mathrm{T}(1 ; 13) 7 \mathrm{OH}$ mouse translocation, the majority of these trisomics are capable of producing offspring (de Boer, 1973; de Boer \& Groen, 1974). The small translocation chromosome $1^{13}$ comprises approximately two-thirds of the length of the shortest autosome.

The litters sired by tertiary trisomic $\left(\operatorname{Ts}\left(1^{13}\right) 7 \mathrm{OH}\right)$ males are generally smaller than normal but the standard deviation of litter size is very wide. The number of females that mate and conceive with these males is also low $(61.5 \%)$. A lowered epididymal sperm count suggested this to be due to a reduced production of spermatozoa with some of them being abnormal (de Boer \& Groen, 1974).

Metaphase II observations in these males indicated that the marker chromosome $1^{13}$ was present in about half of the secondary spermatocytes, which is evidence for $1: 1$ segregation. Karyotyping of fetuses at Days 12 and 19 of gestation yielded $34.6 \%$ tertiary trisomic fetuses at the younger age and $46.3 \%$ at the older age. De Boer \& Groen (1974) explain this unexpected result by suggesting that some tertiary trisomic embryos have died before Day 12 .

The aims of the present investigation were to gain an insight into (1) the number of secondary oocytes fertilized by spermatozoa from tertiary trisomic males; (2) sperm transport in an oligospermic situation; (3) the karyotypes of the fertilizing spermatozoa and the relationship of this parameter to sperm morphology; and (4) whether some of the tertiary trisomic embryos really start to degenerate before Day 12 of gestation.

* Postal address: Department of Genetics, 53 Gen. Foulkesweg, Wageningen, The Netherlands. 


\section{Materials and Methods}

Tertiary trisomic males $\left(\mathrm{Ts}\left(1^{13}\right) 7 \mathrm{OH}\right)$ were in a Swiss random-bred background $(\mathrm{Cpb}(\mathrm{SE}) \mathrm{S})$ and originated from our $\mathrm{Ts}\left(1^{13}\right) 7 \mathrm{OH}$ stock. The males were not more than 5 months of age when they were used for an experiment. The females were all of Swiss random-bred origin and between 2 and 5 months of age when used. Control males were unrelated to the tertiary trisomic males and were from the same Swiss random-bred stock ( $\mathrm{Cpb}(\mathrm{SE}) \mathrm{S})$.

The animals were kept in a lighting regimen of $8 \mathrm{hr}$ dark (01.30-10.30 hours) and food was freely available. The males were housed in the same cages as the females but separated from them by a wire mesh. Males were allowed to mate from 09.30 hours. The females were checked for vaginal plugs at 11.30 and 13.30 hours and killed at 19.00 hours. For histological sections, the ovaries, oviducts and cranial portions of the uterus were fixed in Bouin's fluid for one night. After routine processing sections were cut at $7 \mu \mathrm{m}$ and stained with Feulgen and $1 \%$ light green. With this stain, sperm heads colour bright red, swelling sperm heads violet, interphase nuclei blueish and the cytoplasm and pronuclei variable green, the latter usually somewhat darker. With the day-night scheme employed and taking into account that the midpoint of ovulation in the females falls approximately $4 \mathrm{hr}$ after the midpoint of the dark period (Braden, 1957), the eggs had usually been shed by the time the animals were mated, thus producing a uniform clutch to score for fertilization.

For counts of the number of spermatozoa in the uterus and the oviduct, the two were severed at the uterotubal junction. The uterine horns were flushed with $1 \mathrm{ml}$ sodium citrate buffer, $\mathrm{pH} 6 \cdot 75$, and the sperm density was measured with a haemocytometer. The oviducts were flushed with $0.1 \mathrm{ml}$, using a blunted 30-gauge hypodermic needle inserted through the infundibulum. The flushing was collected in three rings of Vaseline on a slide and the water was evaporated by a current of air. The sperm heads were counted under phase-contrast and subsequently stained by the method of Bryan (1970) using a mixture of $0.1 \%$ eosin-Y, $0 \cdot 1 \%$ fast green and $0.1 \%$ naphthol yellow $\mathrm{S}$ in $1 \%$ acetic acid. A smear prepared from the uterine washings was similarly stained.

Females used for the inspection of 2-cell embryos were kept in the dark between 18.00 and 06.00 hours, and killed on the morning after the day the vaginal plug was found. The oviducts were flushed with Dulbecco A from the ovarian end using a blunted 30-gauge hypodermic needle. When flushing failed, the entire oviduct was torn to pieces. Two-cell eggs with a second polar body which looked normal under a dissecting microscope were discarded. Other eggs were fixed in Heidenhain's fixative, mounted in the usual way (Rafferty, 1970) and stained with lacto-acetic-orcein.

Females from which morulae and blastocysts were to be collected were kept under a day-night schedule of $20 \mathrm{hr}$ light with the dark period from 06.30 to 10.30 hours. With this regimen the differences in developmental stage at the day of autopsy are minimized (Braden, 1957) and the best stage of development for chromosome analysis, $16-32$ cells, is easily obtained. The embryos were recovered in the early afternoon of Day 4 (day of finding vaginal plug = Day 1 ). Chromosome preparations were made according to the method of Tarkowski (1966) and all preparations were treated to show C-bands, indicative for centric constitutive heterochromatin. After the preparations were made, they were post-fixed for $30 \mathrm{~min}$ in Carnoy's fixative, hydrolysed for $1 \mathrm{hr}$ in $0.2 \mathrm{~N}-\mathrm{HCl}$ and thereafter thoroughly dried in a dessicator. C-bands were induced by applying dry heat as described by de Boer \& Groen (1974). The preparations were stained for $45 \mathrm{~min}$ in a $2 \%$ Gurr's improved R66 Giemsa solution made up in Gurr's buffer, $\mathrm{pH} 6 \cdot 8$.

\section{Results}

\section{Sperm counts and morphology}

The sperm counts of the oviductal and uterine flushings and in the oviduct sections are given in Table 1. Only one female was used for each male unless uterine spermatozoa could not be found. The mean values found for the two techniques agree very well, despite the huge variation, and show that the numbers for the tertiary trisomic males are well below those of the controls, being about $10 \%$ for 
the oviduct and uterus. Spearman rank correlation coefficients $\left(r_{s}\right)$ between left and right oviducts have been computed for both techniques and for tertiary trisomic males and controls. The values were high and significant $(P<0.025)$ except for the flushing results of the control males. The same type of correlation was computed for the average number of oviductal spermatozoa per male between the two techniques within the genotypes: for the tertiary trisomics, $\mathrm{r}_{\mathrm{s}}=0.73(0.01<P<0.025)$ and, for the controls, $r_{s}=-0.26$ (N.S.).

Table 1. Counts of spermatozoa obtained by flushing or sectioning of the oviduct and uterus of female mice mated to tertiary trisomic and normal males

\begin{tabular}{lcc}
\hline & $\begin{array}{c}\text { Normal } \\
\text { male }\end{array}$ & $\begin{array}{c}\text { Tertiary trisomic } \\
\text { male }\end{array}$ \\
\hline $\begin{array}{l}\text { Flushing } \\
\text { No. of males }\end{array}$ & 8 & \\
Oviduct & & \\
$\quad$ Mean & $1129 \cdot 5$ & $96 \cdot 72$ \\
$\quad$ Median & $39 \cdot 7$ & $15 \cdot 5$ \\
$\quad$ Range & $30-6614$ & $4-422$ \\
Uterus & & \\
$\quad\left(\times 10^{6}\right)$ & & \\
Mean & $22 \cdot 5$ & $2 \cdot 3$ \\
Median & $22 \cdot 6$ & $2 \cdot 6$ \\
Range & $67-50 \cdot 0$ & $0 \cdot 5-4 \cdot 4$ \\
Sectioning & & \\
No. of males & 9 & 10 \\
Oviduct & & \\
$\quad$ Mean & $1032 \cdot 87$ & $93 \cdot 30$ \\
Median & 691 & $5 \cdot 5$ \\
Range & $14-4015$ & $0-411$ \\
\hline
\end{tabular}

Two reasons may underlie the less consistent results with the control males. First, the repeatability may be less when spermatozoa are more numerous in the ejaculate. Second, the female genital tract responds in a more variable way with large ejaculates, especially when there is variation between the times of mating and autopsy. For the controls, there existed a positive significant rank correlation coefficient between the numbers flushed from the uterus and from the oviducts $\left(\mathrm{r}_{\mathrm{s}}=0.71,0.025<P\right.$ $<0.05$ ), but for the tertiary trisomic males this correlation was significant only when the uterine numbers were corrected for spermatozoa with abnormal morphology $\left(\mathrm{r}_{\mathrm{s}}=0.70,0.01<P<0.025\right)$.

The histological sections enabled a more precise determination to be made of the position of the spermatozoa inside the oviduct. To do this, we have subdivided the oviduct into a portion anterior to the ampulla, the ampulla itself (the extended part containing the eggs) and the isthmus up to the uterotubal junction. The average sperm counts were respectively $0.20,2.45$ and 90.65 for the tertiary trisomic males and $\mathbf{0} \cdot 12,28$ and $\mathbf{1 0 0 4 \cdot 2 8}$ for the control males. Within the isthmus, the distribution was very unequal with almost all of the spermatozoa located in the uterine part of the oviduct.

From the uterine smears 150 spermatozoa of each male were classified morphologically. For the oviducts, as many spermatozoa as possible were scored for their morphology with a maximum of 150 per male.

Of the spermatozoa produced by the tertiary trisomics and found in the uterus, $77 \cdot 2 \%(n=1350)$ were abnormal compared with $9 \cdot 2 \%(n=1200)$ in the control matings. Of spermatozoa in the oviducts, $24.6 \%(n=468)$ from the tertiary trisomic males were abnormal and $1.6 \%(n=1070)$ of those from control males. The oviductal fraction derived from ejaculates of tertiary trisomic and control males contained a higher proportion of normal spermatozoa than the uterine fraction; both $\chi^{2}$ values were significant $(P<0.005)$. The morphologically abnormal spermatozoa were all characterized by an aberrant attachment of the tail to the head which was accompanied by an increasingly symmetrical shape of the head. Tail abnormalities, sometimes in conjunction with the head abnormalities, were 
also encountered, usually in the form of a sharp bend in the midpiece. We had the impression that immature spermatozoa with cytoplasmic droplets were more numerous in the tertiary trisomic males. Spermatozoa with different degrees of abnormality are shown in Pl. 1, Figs 1(a)-1(f).

\section{Fertilization}

For the histological study of eggs around the time of fertilization and thereafter, the same histological material was used as for the sperm counts.

The contents of the oviducts processed between 5.5 and $9.5 \mathrm{hr}$ after mating yielded 114 eggs (out of 20 oviducts) in the group mated to tertiary trisomic males and 81 eggs (out of 17 oviducts) in the control group; 6 eggs were lost for technical reasons. In the control group, all the eggs were fertilized whereas in the matings with tertiary trisomic males, only $34.8 \%$ were fertilized at this stage (Table 2 ). We have taken the relative position of the two pronuclei as an indicator for developmental age within the pronucleus stage: the closer they are located, the nearer they are to syngamy and the older they are. From the results in Table 2 it appears that not only were there more eggs fertilized in the control group but also that they were generally in a more advanced stage of development. The view of Zamboni (1972) that at the time of fertilization there are very few spermatozoa in the ampulla was substantiated. Activated eggs with enlarged sperm heads were found in two oviducts in which no spermatozoa could be traced, and another oviduct contained 2 eggs in the pronucleus stage but only 1 spermatozoon in the isthmus and 9 in the ampulla.

Table 2. The stages of fertilization ( $\%$ in parentheses) in zygotes from matings between normal female mice and normal or tertiary trisomic males

\begin{tabular}{llc}
\hline & $\begin{array}{c}\text { Normal } \\
\text { male }\end{array}$ & $\begin{array}{c}\text { Tertiary trisomic } \\
\text { male }\end{array}$ \\
\hline No. of eggs & 80 & 109 \\
Secondary oocyte & - & $71(65 \cdot 2)$ \\
Spermatozoa in perivitelline space & - & $2(1 \cdot 8)$ \\
Anaphase-telophase II with & $35(43 \cdot 8)$ & $27(24 \cdot 7)$ \\
$\quad$ swollen sperm head & $20(25 \cdot 0)$ & $2(1 \cdot 8)$ \\
Pronuclei in random position & $25(31 \cdot 2)$ & $7(6 \cdot 4)$ \\
Pronuclei close to each other & $100 \%$ & $34.8 \%$ \\
Fertilized &
\end{tabular}

Table 3. The stages of development of embryos (average/female; $\%$ in parentheses) flushed from the oviducts at Day 2 of pregnancy of normal $(+/+)$ female mice mated with normal $(\mathrm{N}=28)$ or tertiary trisomic $(\mathrm{N}=30)$ males

\begin{tabular}{|c|c|c|}
\hline Category & $\begin{array}{l}\text { Tertiary trisomic } \\
\text { male }(n=343)\end{array}$ & $\begin{array}{l}\text { Normal male } \\
\quad(n=283)\end{array}$ \\
\hline 2-Cell, normal & $5 \cdot 73(51 \cdot 52)$ & $9 \cdot 54(94 \cdot 36)$ \\
\hline 2-Cell, abnormal & $0.33 \quad(2.97)$ & $-\quad-$ \\
\hline Pronucleus stage & $0.06 \quad(0.54)$ & $0.11(1.09)$ \\
\hline Secondary oocyte & $3.81(34 \cdot 26)$ & $0.18(1.78)$ \\
\hline Mononucleate & $0.03 \quad(0.27)$ & $0.11(1.09)$ \\
\hline Gynogenesis & $0.06 \quad(0.54)$ & $0.03(0.30)$ \\
\hline 1-Cell, degenerated & $1.00 \quad(9.00)$ & $0.11(1.09)$ \\
\hline Not scorable & $0.10 \quad(0.90)$ & $0.03(0.30)$ \\
\hline Total & $11 \cdot 12$ & $10 \cdot 11$ \\
\hline
\end{tabular}

Table 3 gives the results of the recovery of 2-cell embryos at Day 2 of pregnancy. The males used previously were again used in this investigation. Each male was mated to 3 females. The abnormal 2cell stages were probably fragmented eggs. The pronucleus-stage eggs have been included in the group 


\section{PLATE 1}
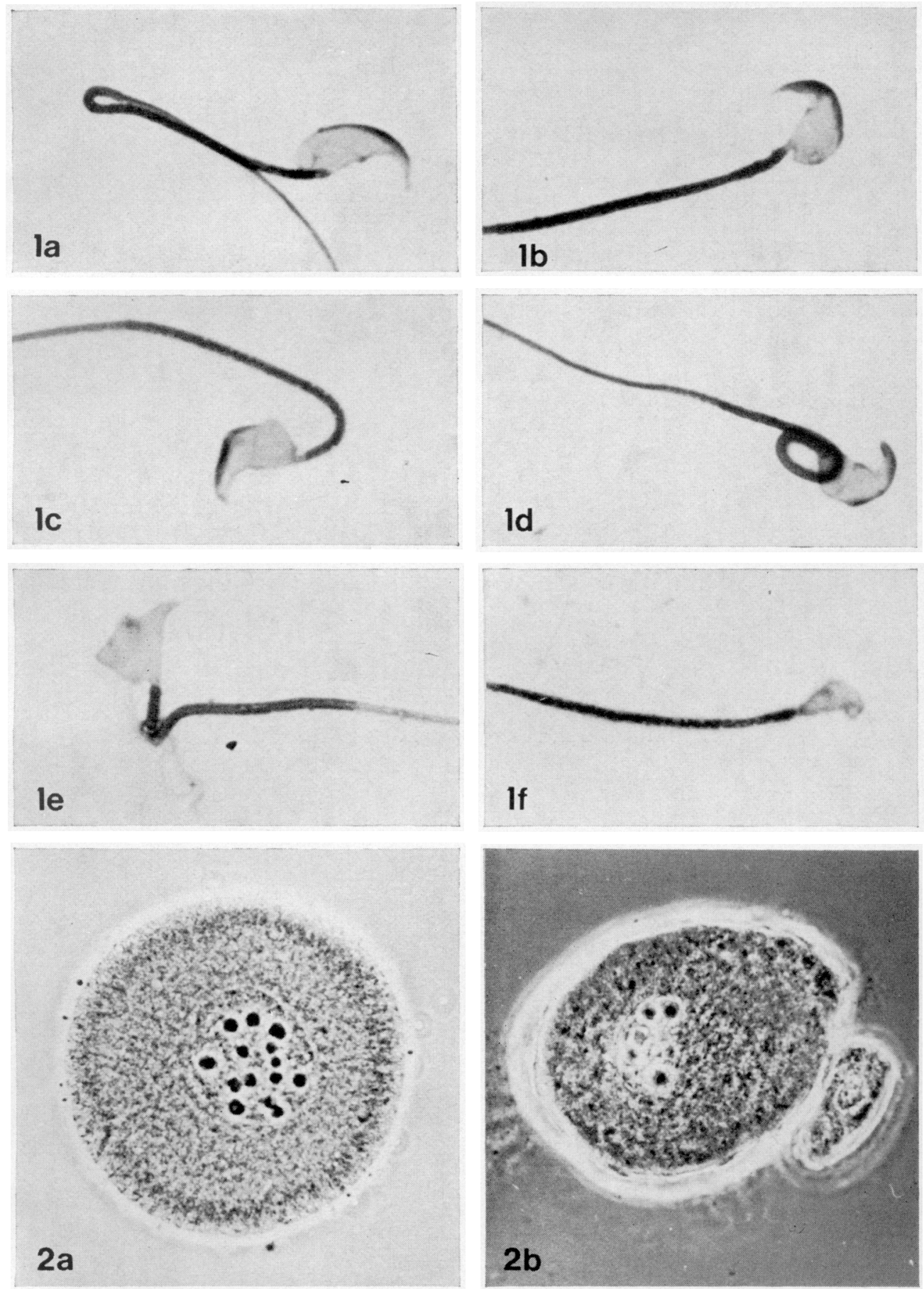

Figs 1(a)-(f). Examples of aberrant sperm heads and tails found in $\mathrm{Ts}\left(1^{13}\right) 7 \mathrm{OH}$ male mice. In (a), the head is normal. The dark areas in (a)-(d) are the acrosomes which have also become abnormal. $\times 1825$.

Fig. 2. Eggs found at Day 2 of pregnancy in normal female mice mated with tertiary trisomic males. (a) A mononucleate egg; (b) a presumptive case of gynogenesis of the same age, with a second polar body and one pronucleus. $\times 730$. 
PLATE 1
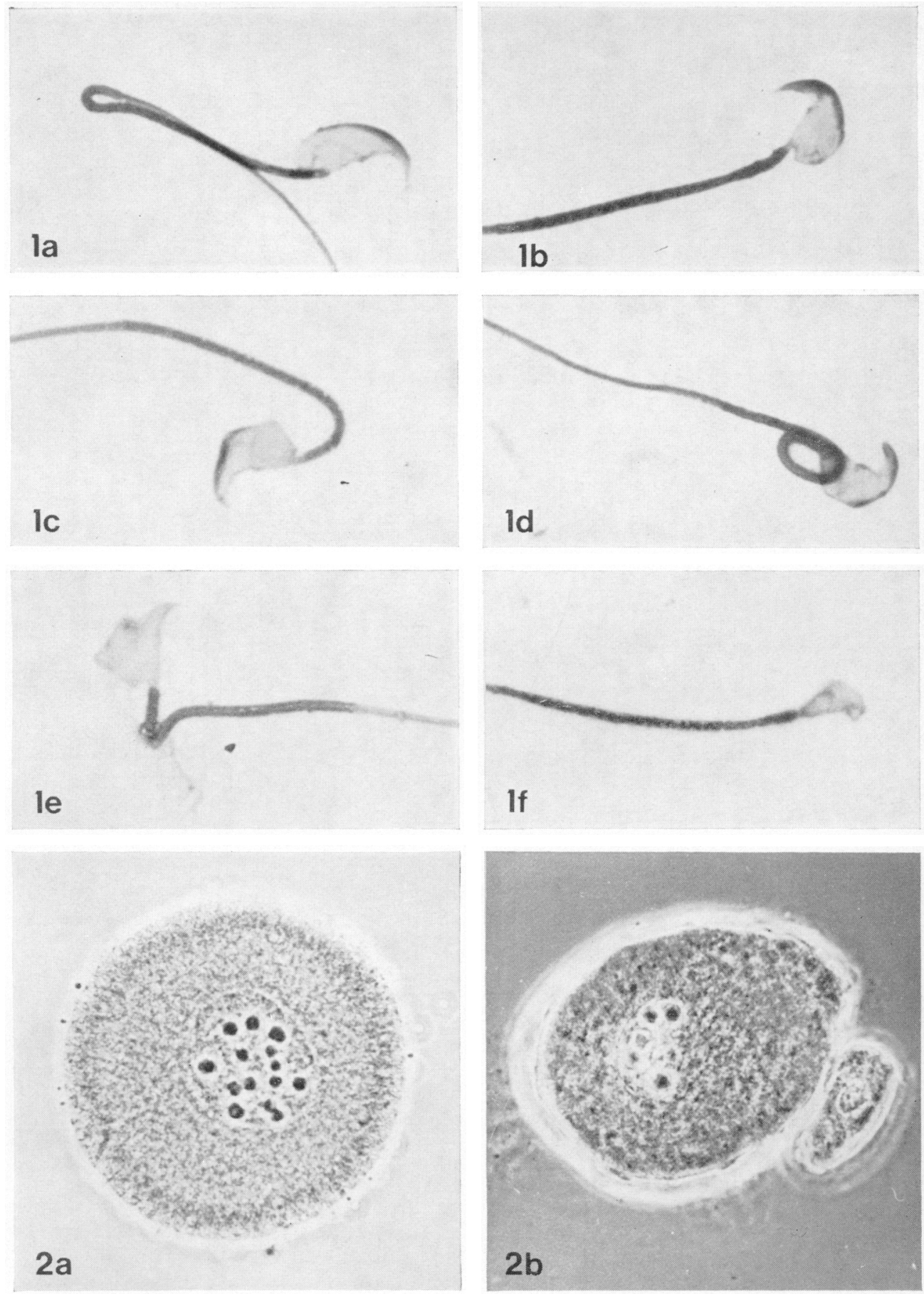

Figs 1(a)-(f). Examples of aberrant sperm heads and tails found in Ts $\left(1^{13}\right) 70 H$ male mice. In (a), the head is normal. The dark areas in (a)-(d) are the acrosomes which have also become abnormal. $\times 1825$.

Fig. 2. Eggs found at Day 2 of pregnancy in normal female mice mated with tertiary trisomic males. (a) $A$ mononucleate egg; (b) a presumptive case of gynogenesis of the same age, with a second polar body and one pronucleus. $\times 730$. 
of fertilized eggs. They are delayed in their development, however, and may represent cases of very early embryonic death. Of the 4 mononucleate eggs found, 3 were in the control series. One was judged to be in diakinesis, the other three (Pl. 1, Fig. 2a) may have been true dictyate oocytes or examples of a restitution nucleus, formed as the result of a faulty first meiotic division. Three cases of gynogenesis were found (Pl. 1, Fig. 2b), two in tertiary trisomic-mated females and one in the controls. In these eggs, no spermatozoon or its tail could be traced, although the second polar body and one pronucleus, presumed to be the female pronucleus, was present. When we include eggs with a male pronucleus, the percentage of fertilized eggs was $52.06 \%$ in the tertiary trisomic group and $95.45 \%$ in the controls. When we compare these results with those from the histological study of eggs recovered between $5 \cdot 5$ and $9 \cdot 5 \mathrm{hr}$ after mating (34.8\% fertilized), the higher percentage of fertilized eggs at Day 2 indicates that the process of fertilization is delayed when there are only few spermatozoa in the oviduct.

\section{The karyotypes of the embryos at Day 4}

Altogether $16 \mathrm{Ts}\left(1^{13}\right) 7 \mathrm{OH}$ males were used of which 13 produced karyotypable embryos. A total of 407 embryos were observed under high power : $29 \cdot 7 \%$ were devoid of divisions, $26.3 \%$ produced divisions either in mitotic prophase or technically unsuitable (mainly broken cells), and the remaining $44 \%$ (179 embryos) were classified as follows:

\begin{tabular}{cccccccc} 
& \multicolumn{3}{c}{ Without $1^{13}$} & \multicolumn{3}{c}{ With $1^{13}$} \\
Chromosome number & 40 & 40 or 41 & 41 & 40 & 40 or 41 & 41 \\
N & 89 & 4 & 2 & 7 & 18 & 59
\end{tabular}

Of the 179 analysable embryos, $46.9 \%$ contained the marker chromosome $1^{13}$. This constitutes no deviation from a hypothetical 1 to 1 segregation in male meiosis of this marker chromosome $\left(\chi_{1}^{2}=\right.$ 0.675 , N.S.). Besides those cases in which there was an overlap of chromosomes and the fact that only very few cells per embryo can be in mitosis giving doubt about the chromosome count, there were two deviant groups : those with 41 chromosomes without chromosome $1^{13}$ and those with 40 chromosomes including chromosome $1^{13}$. The first category is thought to contain primary trisomics for chromosome 13 and their appearance accords with earlier meiotic studies (de Boer \& Groen, 1974). The group with 40 chromosomes including $1^{13}$ must represent the complementary class of embryos that received a paternal contribution lacking a normal chromosome 13. One embryo was considered to be a XXXtriploid without the marker chromosome and polygyny is the most likely explanation for this. A total of 175 embryos could be sexed by means of the C-banding method employed. The sex ratio (number of males per 100 females) was 103.5 which is very close to expectancy. Apparently normal $(+/+)$ embryos had an average developmental stage of $26 \cdot 2$ cells and the tertiary trisomic embryos $25 \cdot 3$ cells. Besides morulae and blastocysts, numerous normal-looking, degenerated and fragmented eggs were found. The average number of eggs and embryos was 8.96 , significantly less than the number of eggs flushed at Day $2\left(t_{153}=4.05, P<0.005\right)$. At Day 4 , the average litter size (morulae plus blastocysts) was $5 \cdot 27(n=81)$, agreeing well with the average number of 2-cell stages found at Day $2(5 \cdot 73, n=30)$, but $2.76 \%$ of 2 -cell eggs of normal appearance was also found.

\section{The effect of age}

During this experiment, there was a general tendency for the tertiary trisomic males to show decreasing fertility with time. When two groups of males matched for parity and mating conditions were compared, those 7-9 months old sired an average of 3.26 embryos at Day $4(n=19)$ and those $3-5$ months old gave 6.90 embryos $(n=20)$. A Wilcoxon signed rank test yielded $\mathrm{W}=281 \cdot 5, \chi=2 \cdot 77$, $0.005>P>0.001$.

\section{The effect of phenotype}

Mice that are tertiary trisomic for chromosome $1^{13}$ occur in a variety of phenotypes (de Boer, 1973; de Boer \& Groen, 1974). The males used in this investigation were separated into those showing 
abnormal growth of the upper and lower incisors and those with normal teeth. Matched for parity and mating conditions, 10 normal males sired an average of $7 \cdot 28$ embryos at Day $4(n=29)$ and 7 abnormal males gave $4 \cdot 24$ embryos $(n=21)$. The difference is significant, using the Wilcoxon signed rank test (W $=413, \chi=2.41,0.01>P>0.005$ ). The effect is mainly due to the fact that among the phenotypically abnormal males there were two which did not produce embryos of normal appearance.

\section{Discussion}

In an earlier investigation (de Boer \& Groen, 1974), one phenotypic characteristic of $\mathrm{Ts}\left(1^{13}\right) 7 \mathrm{OH}$ male mice was their low sperm count $(28.5 \%$ of normal) inside the caput epididymidis. As shown in the present report, this leads to very low numbers ( $\bumpeq 10 \%$ of normal) in the isthmus after copulation. Since approximately $75 \%$ of the oviductal spermatozoa look normal, the number of apparently functional spermatozoa is about $7.5 \%$ of the control value. The reproductive process can still go on at this level, because most of the mutant males yielded fertilized eggs and embryos. Thus, the mouse withstands oligospermy better than man, in which counts lower than $25 \%$ of normal $\left(<20 \times 10^{6} / \mathrm{ml}\right.$ ejaculate) give rise to subfertility. Our results agree with those of Searle \& Beechey (1974) who found that, after X-ray-induced oligospermy in mice, the percentage of eggs fertilized drops when the epididymal sperm count falls below $10 \%$ of normal. As found by Krzanowska (1974) and Stolla \& Gropp (1974), there seems to be an efficient selection against abnormally shaped spermatozoa at the uterotubal junction. Olds (1970), however, in her work on male-sterile combinations of $t$-alleles could not substantiate this effect. She was also unable, contrary to our findings, to demonstrate an inverse relationship between the percentage of abnormal spermatozoa in the lower tract and the total number of spermatozoa from oviductal flushings.

In a pilot experiment to see whether there was any relationship between sperm motility and morphology, the morphology of uterine spermatozoa from two Ts $\left(1^{13}\right) 7 \mathrm{OH}$ males was scored under low power, before and after cooling. Before cooling, the total motility was assessed to be $70-80 \%$. Of the non-motile spermatozoa, $17.6 \%(n=176)$ appeared to be of normal shape. After $1 \mathrm{hr}$ at $4^{\circ} \mathrm{C}$, when almost no motility was left, $35 \%(n=576)$ seemed to be normal. We therefore suggest that, in the sperm population described here, there is a relationship between morphology and motility, with normal spermatozoa showing the best motility. The relationship between sperm motility and fertilization is well known in mammals. In the rat, dead spermatozoa cannot pass through the uterotubal junction (Leonard \& Perlman, 1949). Ginsberg \& Hillman (1974) considered it most likely that the increased oxygen uptake by $t^{n}$-bearing spermatozoa leads to an increased motility which, in turn, results in an increased transmission of the gene. Altogether, we believe that normal motility is required for mouse spermatozoa to enter the oviduct.

About $75 \%$ of the spermatozoa from $\mathrm{Ts}\left(1^{13}\right) 7 \mathrm{OH}$ males were morphologically normal when recovered from the oviduct, and about half of these possess the small marker chromosome $1^{13}$. Keeping in mind that euploid and aneuploid spermatozoa must be formed in about equal numbers (see 'Introduction') we have not found any indication for a relationship between sperm morphology and karyotypic abnormality. The impaired morphology of the majority of spermatozoa from the tertiary trisomic males must therefore be a function of the testis and epididymis. Independence of the functioning of male and female gametes from their chromosomal constitution has already been stated by others (see Ford, 1972), but in those cases the chromosomal unbalance did not occur in a population of mainly morphologically abnormal gametes.

Oligospermy in the tertiary trisomic males leads to delayed fertilization. In general, anomalies associated with delayed fertilization are mononucleate eggs, polygyny (suppression of second polar body formation), the formation of two second polar bodies, the formation of a very large second polar body, and polyspermy (Donahue, 1975). The last phenomenon may be discounted here because of the presence of oligospermy. Only one example of triploidy was encountered which, out of a total of 179 , is not higher than the incidence of $0.5 \%$ reported by Ford \& Evans (1973) for a large series (1924) of 8-11-day-old embryos. The frequency of mononucleate eggs at Day 2 was not increased, nor was gynogenesis without cleavage, which could also result from delayed fertilization (Graham, 1974). 
Higher levels of triploidy have been reported mainly after superovulation (Donahue, 1972; Kaufman, 1973; Takagi, 1970) and after superovulation combined with delayed fertilization (Vickers, 1969). We agree with Gates \& Beatty (1954) (who used superovulation as well) and Braden \& Austin (1954) that there is virtually no triploidy in most mouse strains, even when fertilization is delayed.

'Ghost'-like and fragmented eggs persisted in remarkable numbers up to Day 4, mostly in the uterus. The fraction of unfertilized eggs that persist must be higher at Day 4 than the $50 \%$ reported by McLaren \& Orsini (1968) who found no 2-cell stages of normal appearance at this time whereas we found $2.76 \%$, originating from several males. So the phenomenon might be caused by a situation of oligospermy combined with delayed fertilization.

The association of oligospermy (and azoospermy) with chromosomal abnormalities is well known in mammalian cytogenetics. In the mouse, it not only occurs in the tertiary trisomic condition, but it can also be expected in the case of balanced reciprocal translocations induced in spermatogonia (Ford, Searle, Evans \& West, 1969) and in spermatozoa (Searle et al., 1974). The most detailed studies have been on males heterozygous for the T6Ca translocation, which have $88.8 \%$ abnormal spermatozoa (Wyrobek, Heddle \& Bruce, 1975). In man such cases have been described by Chandley, Christie, Fletcher, Frackiewicz \& Jacobs (1972), and sperm counts are reduced in patients with Down's syndrome (Penrose \& Smith, 1966). Radiation studies on spermatogonia especially point to the fact that spermatogenesis is a process which is excessively sensitive to chromosome mutation. This acts as a partial selection barrier against the occurrence of chromosome mutants in the population. The male tertiary trisomic mice described in this investigation have escaped this selection criterion and at least some functional spermatozoa are produced.

The frequency of tertiary trisomic embryos at Day 12 was earlier estimated to be $34.6 \%(n=130)$ (de Boer \& Groen, 1974). From the present data for Day-4 embryos, the estimate is $77 / 170$ (45.3\%). This difference, tested as a heterogeneity $\chi^{2}$ is significant $(\chi=1.87,0.025<P<0.05)$ and confirms our earlier belief that some of the tertiary trisomic embryos die before Day 12 . Gropp, Giers \& Kolbus (1974), in a systematic investigation of the developmental capacities of different primary trisomic conditions, found that primary trisomics for chromosome 1 and 13 die between Days 13 and 15. Probably, the least viable $\mathrm{Ts}\left(1^{13}\right) 7 \mathrm{OH}$ embryos do not die earlier than the weakest primary trisomies for the chromosomes 1 and 13, but their variance inlife expectancy is considerably increased. The viability within the $\mathrm{Ts}\left(1^{13}\right) 7 \mathrm{OH}$ karyotype so far remains unexplained.

We are very grateful to Mr C. V. Beechey and Dr A. G. Searle for commenting on the manuscript.

\section{References}

BradeN, A.W.H. (1957) The relationship between the diurnal light cycle and the time of ovulation in mice. J. exp. Biol. 34, 177-188.

Braden, A.W.H. \& Austin, C.R. (1954) Fertilization of the mouse egg and the effect of delayed coitus and of hot-shock treatment. Aust. J. biol. Sci. 7, 552-565.

BRYAN, J.H.D. (1970) An eosin-fast green-naphthol yellow mixture for differential staining of the cytologic components in mammalian spermatozoa. Stain Technol. 45, 231-236.

Chandley, A.C., Christie, S., Fletcher, J., FrackiewICZ, A. \& JACOBS, P.A. (1972) Translocation heterozygosity and associated subfertility in man. Cytogenetics 11, 516-533.

De BoER, P. (1973) Fertile tertiary trisomy in the mouse (Mus musculus). Cytogenet. Cell Genet. 12, 435-442.

DE Boer, P. \& Groen, A. (1974) Fertility and meiotic behavior of male $\mathrm{T} 7 \mathrm{OH}$ tertiary trisomics of the mouse (Mus musculus). Cytogenet. Cell Genet. 13, 489-510.

Donahue, R.P. (1972) Cytogenetic analysis of the first cleavage division in mouse embryos. Proc. natn. Acad. Sci. U.S.A. 69, 74-77.

DoNAHUE, R.P. (1975) Normal and abnormal chromosomal behavior in the meiotic divisions of mammalian oocytes. In Aging Gametes, pp. 50-71. Ed. R.J. Blandau. S. Karger, Basel.

Ford, C.E. (1972) Gross genome unbalance: does it influence the capacity to fertilize. In Genetics of the Spermatozoon, pp. 359-369. Eds R.A. Beatty \& S. Gluecksohn-Waelsch. Edinburgh.

Ford, C.E. \& Evans, E.P. (1973) Non-expression of genome imbalance in haplophase and early diplophase of the mouse and incidence of karyotypic abnormality in post-implantation embryos. In Chromosomal Errors in Relation to Reproductive Failure, pp. 271- 
285. Eds A. Boué \& C. Thibault. INSERM, Paris.

Ford, C.E., Searle, A.G., Evans, E.P. \& JeAN West, B. (1969) Differential transmission of translocations induced in spermatogonia of mice by irradiation. Cytogenetics 8, 447-470.

Gates, A.H. \& BeatTy, R.A. (1954) Independence of delayed fertilization and spontaneous triploidy in mouse embryos. Nature, Lond. 174, 356-357.

Ginsberg, L. \& Hillman, N. (1974) Meiotic drive in $t^{\mathrm{n}}$-bearing mouse spermatozoa: a relationship between aerobic respiration and transmission frequency. J. Reprod. Fert. 38, 157-163.

GraHAM, C.F. (1974) The production of parthenogenetic mammalian embryos and their use in biological research. Biol. Rev. 49, 399-422.

Gropp, A., Giers, D. \& Kolbus, U. (1974) Trisomy in the fetal backcross progeny of male and female metacentric heterozygotes in the mouse. I. Cytogenet. Cell Genet. 13, 511-535.

Kaufman, M.H. (1973) Analysis of the first cleavage division to determine the sex-ratio and incidence of chromosome anomalies at conception in the mouse. J. Reprod. Fert. 35, 67-72.

Krzanowska, H. (1974) The passage of abnormal spermatozoa through the uterotubal junction of the mouse. J. Reprod. Fert. 38, 81-90.

Leonard, S.L. \& Perlman, R.L. (1949) Conditions effecting the passage of spermatozoa through the uterotubal junction of the rat. Anat. Rec. 104, 89-101.

MCLAREN, A. \& ORSINI, M.W. (1968) The fate of unfertilized eggs in mice. J. Reprod. Fert. 15, 181-183.

OLDs, P.J. (1970). Effect of the T locus on sperm distribution in the house mouse. Biol. Reprod. 2, 91-97.
Penrose, L.S. \& Smith, G.F. (1966) Down's Anomaly. J. \& A. Churchill Ltd, London.

RAFFERTY, K.A. (1970) Methods in Experimental Embryology of the Mouse. Johns Hopkins Press, Baltimore.

Searle, A.G. \& Berchey, C.V. (1974) Sperm-count, egg-fertilization and dominant lethality after $\mathrm{X}$ irradiation of mice. Mutation Res. 22, 63-72.

Searle, A.G., Ford, C.E., Evans, E.P., Beechey, C.V., Burtenshaw, M.D. \& ClegG, H.M. (1974) The induction of translocations in mouse spermatogonia. I. Kinetics of dose response with acute $\mathrm{X}$-irradiation. Mutation Res. 22, 157-174.

STOLla, R. \& GropP, A. (1974) Variation of the DNA content of morphologically normal and abnormal spermatozoa in mice susceptible to irregular meiotic segregation. J. Reprod. Fert. 38, 335-346.

TAKAGI, N. (1970) High incidence of triploid embryos associated with artificial polyovulation in mice. Chrom. Inf. Ser. 11, 35.

TARKowski, A. (1966) An air-drying method for chromosome preparations from mouse eggs. Cytogenetics $\mathbf{5}$, 394400.

Vickers, A.D. (1969) Delayed fertilization and chromosomal anomalies in mouse embryos. J. Reprod. Fert. 20, 69-76.

WyrobeK, A.J., Heddle, J.A. \& BruCE, W.R. (1975) Chromosomal abnormalities and the morphology of mouse sperm heads. Can.J. Genet. Cytol.17, 675-681.

ZAMBONI, L. (1972) Fertilization in the mouse. In Biology of Mammalian Fertilization and Implantation, pp. 213-262. Eds K.S. Moghissi \& E.S.E. Hafez. C.C. Thomas, Springfield, Illinois.

Received 16 January 1976 